\title{
Groundless Research Published on the International Journal of Plant Sciences
}

\author{
Xin Wang \\ State Key Laboratory of Palaeobiology and Stratigraphy, Nanjing Institute of Geology and Palaeontology and Center for \\ Excellence in Life and Paleoenvironment, Chinese Academy of Sciences, Nanjing, China \\ Email: xinwang@nigpas.ac.cn
}

How to cite this paper: Wang, X. (2020). Groundless Research Published on the International Journal of Plant Sciences. Voice of the Publisher, 6, 167-169.

https://doi.org/10.4236/vp.2020.64020

Received: October 19, 2020

Accepted: November 24, 2020

Published: November 27, 2020

Copyright () 2020 by author(s) and Scientific Research Publishing Inc. This work is licensed under the Creative Commons Attribution International License (CC BY 4.0).

http://creativecommons.org/licenses/by/4.0/

\begin{abstract}
Two recent publications from basically the same authors challenge the intelligence and wisdom of all botanists. The conflict between Friis et al. and Herendeen et al. defies all people in favor of Friis et al.: Friis, Crane and Pedersen are fighting against themselves. Taking either side offends Friis et al. Furthermore, based on an artificially fabricated feature, Friis et al. placed a new fossil genus Hedyflora into the Chloranthaceae (Angiosperms). The validity of this taxon is spurious. If this taxon were accepted, botany would appear approaching an art rather than a science.
\end{abstract}

\section{Keywords}

Hedyflora, Self-Contradiction, Botany, Science, Art

\section{Introduction}

The study on early angiosperms is one of the most controversial topics in botany, simply because different scholars have different criteria identifying fossil angiosperms. However, there was no single scholar overruling himself on this issue until recently: This unprecedentedly ridiculous situation finally occurred in science.

\section{Criterion and Interpretations}

According to Herendeen et al. (2017), an angiosperm fossil is assumed to have certain "unique angiosperm features" including "tetrasporangiate dithecate stamens with four pollen sacs arranged in two pairs, pollen grains with multiple apertures in a radially symmetrical or global arrangement, and carpels enclosing one or several bitegmic ovules with two integuments" (Herendeen et al., 2017). This criterion remains unchanged by the authors since 2017. Hedyflora, the fossils reported in Friis et al. (2019), has NONE of these features: there is NO sta- 
men, the associated pollen grains are monoaperturate (not multiaperturate), the carpel is skeptical, and the claimed "bitegmic" ovule does NOT exist. Therefore, if the criterion advanced by Herendeen et al. (2017) were adopted, Hedyflora would not be an angiosperm, not mention Chloranthaceae. This means that Friis et al. (2019) and Herendeen et al. (2017) are against each other on the angiospermous affinity of Hedyflora. Although controversy is a routine and healthy existence in study of early angiosperms, the conflict between Friis et al. (2019) and Herendeen et al. (2017) is unprecedented: Friis, Crane, and Pedersen are the major members shared between these two conflicting parties. This situation appears defying the intelligence of all scientists, especially botanists. A question naturally arises in my mind: Who on the earth tried to cheat me and all other scientists, Friis, Crane, Pedersen, Herendeen, or all of them?

According to Friis et al. (2019), "pendant, orthotropous, and bitegmic ovule" is a key feature of all chloranthaceous plants. The word "ovule" and "ovules" have occurred four times in total in Friis et al. (2019), but NONE in the figure captions. In the fossil description, they mentioned the word "ovule" but failed to cite any figure to support their claim. Both facts imply that Friis et al. were aware of the LACK of ovule in their fossils. If there is NO ovule, then, naturally, there is NO "pendant, orthotropous, and bitegmic ovule". If so, then where came the feature of "pendant, orthotropous, and bitegmic ovule" in the diagnosis of $\mathrm{He}$ dyflora? How did they manage to fabricate this feature out of nothing and pass ALL the reviewings? Will these questions become a skeleton in the closet in science? If a feature so crucial for the Chloranthaceae is proven faked, will there still be a valid taxon named Hedyflora?

\section{Conclusion}

To elucidate the situation and avoid further confusion, Friis, Crane and Pedersen have to clearly declare which of the two conflicting parties they finally take, Friis et al. (2019) or Herendeen et al. (2017)? The genus Hedyflora cannot be a valid botanical name except Friis et al. could convincingly demonstrate the presence of the claimed ovule(s). If they could, another question naturally arising would be "How could the feature be missed initially"? Under the current condition, if Hedyflora were accepted, botany (although a science) would end up to be an art sooner or later.

\section{Note}

The author has written to the International Journal of Plant Sciences, the University of Chicago Press, and the University Chicago on this issue. Only the chief editor of the International Journal of Plant Sciences responded by writing "We recently completed our investigation of your complaint, and did not find a basis for retracting Friis et al. (2019)." The Press and University remain silent on this issue so far.

\section{Fund}

This research is supported by the Strategic Priority Research Program (B) of 
Chinese Academy of Sciences (XDB26000000), National Basic Research Program of China (2012CB821901), and National Natural Science Foundation of China (41688103, 91514302, 41572046).

\section{Conflicts of Interest}

The author declares no conflicts of interest regarding the publication of this paper.

\section{References}

Friis, E. M., Crane, P. R., \& Pedersen, K. R. (2019). Hedyosmum-Like Fossils in the Early Cretaceous Diversification of Angiosperms. International Journal of Plant Sciences, 180, 232-239. https://doi.org/10.1086/701819

Herendeen, P. S., Friis, E. M., Pedersen, K. R., \& Crane, P. R. (2017). Palaeobotanical Redux: Revisiting the Age of the Angiosperms. Nature Plants, 3, 17015.

https://doi.org/10.1038/nplants.2017.15 